\title{
The Emergence of a Globalized System for Disaster Risk Management and Challenges for Appropriate Governance
}

\author{
Steven J. Jensen • Shirley Feldmann-Jensen • \\ David M. Johnston • Nancy A. Brown
}

Published online: 25 February 2015

(c) The Author(s) 2015. This article is published with open access at Springerlink.com

\begin{abstract}
Disaster risk management (DRM) is undergoing noteworthy changes, reflecting the broader shifts in global and local levels of governance. At the global level two significant changes are of interest: (1) the shift from monolithic structures of global governance to a wide range of organizations that can be brought together for specific purposes and (2) the emergence of a globalized system of DRM, with technological, organizational, and institutional capacities enhancing DRM's ability as a unit in near real time across the globe. At the local level there is an increase in ability to govern and develop creative solutions for complex problems that follow rapid urbanization. The importance of getting the global-local interface to work in tandem has been highlighted by recent hazard events, such as the 2011 Tohoku Earthquake and Tsunami. From a broad view of global and local shifts, a strategic role is becoming clearer at the national level for enhancing the relationships between the global and local levels. Through the influence of a globalized system of DRM, the local level can significantly improve its capacity without the heavy investment that might have been required to develop these capacities in isolation. One key to achieving this is a
\end{abstract}

S. J. Jensen $(\varangle) \cdot$ S. Feldmann-Jensen · N. A. Brown College of Health and Human Services, California State University, Long Beach, CA 90840, USA

e-mail: stevenjohnjensen@gmail.com

D. M. Johnston

GNS Science, Lower Hutt 5040, New Zealand

D. M. Johnston

School of Psychology, Joint Centre of Disaster Research, Massey University, Wellington 6140, New Zealand diffusion of DRM higher education, supported by an enhanced system of information flow.

Keywords Disaster risk management - Global governance - Globalization - Globalized systems · Local governance $\cdot$ National governance

\section{Introduction}

The way disaster risk management (DRM) is conducted has been reshaped by the processes often referred to as globalization. Technological innovation in communications has fundamentally driven the transformation of the global economy and with it the way our world is structured. Likewise, these global influences have also concentrated risk in both scale and complexity. As the world steadily becomes more interconnected and interdependent, the dynamics of DRM continue to transform. It is in the midst of these processes that new patterns of DRM relationships between local, national, and global levels of governance have emerged.

One indicator of the adaptation in DRM is the differences seen in disaster response over the past decade, where the events in Indonesia, Thailand, Pakistan, Haiti, Chile, New Zealand, Japan, and the Philippines have increasingly given rise to a more coordinated and integrated global system. Further evidence can be seen in the wide attempts to create more resilient communities, demonstrated from preparedness efforts of the local level all the way to growth in management and mitigation systems at the global level. Simultaneously, the complexities of emerging risk patterns necessitate innovative approaches in DRM. A basis for new strategies may lie within the changed patterns of relationships between the levels of DRM. 
Shifts in functionality have also been observed in disaster risk governance at global, national, and local levels. This descriptive analysis presents a broad view of the dynamic transformation underway in governance at the global and local levels. Delineated below is a brief highlight of the noted changes among the levels of disaster risk governance.

- The global level evidences two significant changes. Primarily, the monolithic structures of global governance have shifted to encompass a wide range of organizations, which can be brought together for specific purposes. Accompanying this networked capacity of multiple groups is the emergence of a globalized DRM system.

- The local level is showing an increase in ability to govern and develop creative solutions for complex local problems confronting individual urban areas. Rapid urbanization is resulting in strong growth in smaller cities, which are also facing elevated levels of risk with the increased density of population and built environment. A wide diffusion of capacity across the spectrum of growing cities has been necessitated by the complexity of risk that has evolved.

- While the national level may be experiencing the disconcerting effects of the above changes, new opportunities exist to act strategically in strengthening links between global and local capacities. The national level can be a critical central node that enhances DRM coordination and strength. National DRM providing a strong complement to the predominant global and local capacities can offer important gains for overall DRM effectiveness.

Whether these changes reflect a period of convergence, or random disconnected changes on a global scale, it is incumbent to understand the nature of the changes and the opportunities presented for improving DRM approaches. Further, these governance changes suggest there could be important implications for DRM at the national level.

New ways to integrate DRM efforts between sectors and levels of governance are beginning to emerge. The World Economic Forum has recognized the challenge of globallocal coordination in its most recent Global Risk Report:

The systemic nature of our most significant risks calls for procedures and institutions that are globally coordinated yet locally flexible. As international systems of finance, supply chains, health, energy, the Internet and the environment become more complex and interdependent, their level of resilience determines whether they become bulwarks of global stability or amplifiers of cascading shocks. Strengthening resilience requires overcoming collective action challenges through international cooperation among business, government and civil society (WEF 2014, p. 9).

Adaptation can be in temporary arrangements, as was seen in the response to piracy off East Africa. More permanent solutions, such as the formation of the G20 in response to the recent global financial crisis, are also evidenced. The primary evolution is that capacities can be supported and enhanced through the interconnections of the global-national-local spectrum when needed.

\section{International Governance and Globalized Systems}

In recent years, significant transformations have occurred in global governance. Two different but related global level developments have changed the potential for doing DRM: (1) An alteration in international governance practice; and (2) The formation of a globalized system in DRM. Functionally, the two are nested and interact in diverse ways. The result is a dynamic mix of many types of organizations that can come together for specific requirements. This network pattern does not reflect a wellorganized system, yet it can be surprisingly nimble and accessible.

A patchwork of organizations and mechanisms now stand alongside the United Nations and the more traditional international bodies. Patrick (2014, p. 59) describes this emerging global arrangement as "the continued spread of an unattractive, but adaptable multilateral sprawl that delivers a partial measure of international cooperation through a welter of informal arrangements and piecemeal approaches." Examples of such organizations include: "regional institutions; multilateral alliances and security groups; standing consultative mechanisms; self-selecting clubs; ad hoc coalitions; issue-specific arrangements; transnational professional networks; technical standard-setting bodies; and global action networks" (Patrick 2014, p. 59). These organizations are able to selforganize in an ad hoc manner, where components from diverse organizations assemble for specific projects and functions. The emerging global arrangement may not have the grace and gravitas of a United Nations; yet, such evolving networked and globalized processes are the reality of the world today.

As an example of this "adaptable multi-lateral sprawl," the 2014 Ebola response in West Africa required a combination of specific capacities that did not exist in one monolithic organization. Even though the World Health Organization (WHO) stumbled with its response, the international system demonstrated surprising litheness as components rearranged from an array of sectors and 
governance levels to counter the deadly outbreak with world-wide implications. Dr. Margaret Chan, DirectorGeneral WHO, described the extent of the Ebola response: "Development partners, including many African countries, provided funds, equipment, mobile laboratories, and training. Foreign military personnel provided logistical support and constructed new treatment facilities[...] Researchers, the pharmaceutical industry, and regulatory authorities joined forces to fast-track the development of Ebola vaccines, therapies, and point-of-care diagnostic tests" (WHO 2015). Capacities were rapidly assembled into an agile organization, similar to the project focused ad hoc networked organizations brought together for complex projects in the information technology (IT), aerospace, and a host of other industries that regularly deal with massive complex projects. Such deep collaborations may be messy and unattractive, but in the case of Ebola they got the job done. More importantly, lessons were learned and to some degree reforms are taking place in global health governance (WHO 2015). The Ebola response was not unique. Similar processes can also be seen in the response to threats ranging from East African piracy to the 2008 financial crisis (Patrick 2014).

An important product of the "adaptable multi-lateral sprawl" is the emergence of a globalized system in DRM. Globalization has been described by Castells (2008, p. 81) as "the process that constitutes a social system with the capacity to work as a unit on a planetary scale in real or chosen time." The processes of present-day globalization are reliant upon three foundational capacities: technological, organizational, and institutional (Castells 1996). Primarily, the technological developments of the past 70 years in computerized communications, Internet connectedness, and transportation mobility have facilitated the transformation of interdependent global systems such as banking and air travel. Although the whole world is not globalized, all regions have critical processes that are supported by globalized networks (Castells 2008).

Importantly, the components of the emerging DRM globalized system can be grouped along the lines identified by Castells (1996) for a globalized system to develop: technological, organizational, and institutional capacities. When considered in terms of the three capacities, the transpiring DRM globalized system, it can be argued that a "threshold" has been passed, and a system of globalized system of DRM has become adequately developed and functional. While a detailed analysis of the range of recent developments that constitute this system across the globe is beyond the scope of this article, the interdependent systems now in place in relationship to the three capacities is described.

\subsection{Technological Capacities}

The DRM community was an early adopter of emerging information and communication technologies (ICT) platforms, though industries such as finance and transportation have been much more adept at enhancing operations with ICT. Major thrusts in the general development and application of ICT go back to the 1970s, with a concerted effort to implement ICT in DRM starting in the early 1990s.

The judicious application of technology is enabling stronger and interconnected DRM. The National Research Council (NRC), under direction of the U.S. Congress, identified the following improvements to DRM through ICT (NRC 2007, p. 6-7):

- More robust, interoperable, and priority-sensitive communications.

- Enhanced situational awareness and common operating picture.

- Improved decision support and resource tracking and allocation.

- Greater organizational agility for disaster management.

- Better engagement of the public by (1) supplying information and (2) making use of information and resources public participants can supply.

- Augmented infrastructure survivability and continuity of societal functions.

ICT has enabled better communications, remote sensing, monitoring networks, warning systems, and modelling and geospatial technologies. Social media communication programs are now commonplace and widely used at all levels of DRM. The inherent redundancy and robust qualities built into the Internet system have leveraged a wide range of this technology through enhancement of capabilities and enabling rapid diffusion.

Despite the significant advantages of ICT, uneven ICT adoption within and between countries becomes a DRM limitation. As an example, the uneven distribution of warnings in the 2004 Indian Ocean tsunami resulted in many thousands of avoidable deaths. In a much different setting, during Hurricane Katrina in 2005 the inadequate monitoring of infrastructure and failed warning systems led to hundreds of avoidable deaths. While these deficiencies have been addressed, the uneven uptake of ICT tends to disproportionately affect the more vulnerable populations. More generally referred to as the "digital divide," this uneven adoption of ICT tends to exacerbate economic differences. For DRM, the uneven adoption of ICT disproportionately affects the most vulnerable and slows the extension of DRM advances where they are needed most. 


\subsection{Organizational Capacities}

The past 50 years have seen rapid growth in both the quantity and quality of organizations with a DRM role. Diverse forms of DRM organizational capacity are evidenced, from simply building DRM capacity within an organization to the development of purpose-built DRM organizations with unique missions. Most firms recognize that they need to develop the ability to keep their people reasonably safe, others recognize the importance of maintaining systems and are willing to invest substantially to ensure continuity of their operations, and additional organizations have multiple roles with significant disaster responsibilities.

Some examples of DRM organizations with specialized disaster functions include scientific understanding of hazards and social processes; management of financial risk; insurance, re-insurance, and their support organizations; civil society organizations; universities with a range of disaster-related higher education offerings; technical and engineering firms with disaster relevant specialties; DRM consulting; military support to civilian operations; disaster response; and media organizations that have a deeper understanding of disaster. Ensuring organizational stability necessitates a complex array of academics, consultants, websites, courses, software, tools, laws, and standards.

It is difficult to count the growth in organizations active in disaster globally. One measure is the number of organizations actively providing content to ReliefWeb, ${ }^{1}$ the UN Office for the Coordination of Humanitarian Affair's (OCHA) on-line source of information on global crisis and disasters. At the beginning of 2015 there were 2,852 active organizations, which represent a wide range of capabilities and capacities. Beyond the number of organizations doing the work is a rising professionalization, providing a higher quality DRM than may have been in place 20 years ago. Add to this the synergistic effects of diverse organizations with complementary functions working together on specific projects, such as the Ebola outbreak, and the potential for DRM organizations is significantly leveraged. ICT makes it easier to tie together the work of different organizations with the communities they serve and institutional arrangements allow for these processes to be better defined.

\subsection{Institutional Capacities}

The third part of a globalized system refers to institutionally linking the work of diverse organizations. Some recent developments in this area include DRM-related institutions focusing on coordination, standards, guidance, incident

\footnotetext{
${ }^{1}$ http://reliefweb.int/.
}

management systems, information dissemination, and sense-making.

As an example of institutional arrangements, UN OCHA was established for the better management of international humanitarian responses and extended through much of the UN system. Within this system is the Inter-Agency Standing Committee (IASC), which serves as the primary mechanism for inter-agency coordination of assistance. The "cluster approach" was developed as one way to optimize the use of international resources during disaster response operations.

There has been a proliferation of international frameworks and standards covering various aspects of DRM. Examples include the Hyogo Framework, the Sphere Humanitarian Charter and Minimum Standards, the ISO 9000 series, ISO Societal Security and NFPA 1600. These frameworks and standards are relatively new, but have provided effective reference points for the type of interorganizational work that characterizes DRM.

The trajectory of the developments over the last 70 years reveals a remarkable building of ICT, organizational, and institutional capacities. Interactions among a wide range of capacities allow these components to coalesce into a functioning globalized system with synergistic capacities well beyond the sum of the individual elements.

This emerging globalized system for DRM is a network consisting of loose connections and agreements, and can be referred to as a "nobody in charge" system. Cleveland (2002) refers to such networked organizations as "uncentralized" systems. Similar examples include the Internet, VISA credit card system, and the International Organization for Standardization. The idea is that these networks have not decentralized, as they never were centralized, but function quite well without central control. This "uncentralized" dynamic parallels the "adaptable multi-lateral sprawl" that Patrick (2014) uses to describe modern international efforts to resolve specific issues.

Each of these ICT, organizational, and institutional capacities is to some degree complementary to the other capacities. For example, in Japan's 2011 Tohoku Earthquake and Tsunami, remote sensing systems and social media reports were leveraged by the analysis and depiction afforded through geospatial technologies, which in turn were nested in wider ICT through the Internet. This capability allowed "sense-making" to be provided by a range of experts scattered around the world. In this way a globalized system of DRM was able to very quickly enable a diverse set of international stakeholders to self-synchronize as they reacted to the many implications of this disaster. Thus the underlying strength of the emerging system is found in the synergies that develop as diverse and complementary components interact. 
There are gaps and overlaps in the components of this globalized system of DRM, yet a system now exists that is capable of functioning with diverse components that are self-synchronizing in real time, throughout multiple locations, and across the planet. The description is much like that of more familiar globalized systems. As such, DRM is nested within other globalized systems that interact as required. For example, globalized finance systems and global transportation are constantly readjusting to changes in industry and energy systems and now DRM as was seen in the rapid adjustments to the Tohoku Earthquake and Tsunami in Japan.

\section{Local Governance and Growth of Cities}

Demographic trends reveal a substantial change in how people live on the earth. The world is urbanizing with $54 \%$ of its population living in cities in 2014. In 1950, this number was $30 \%$ and by 2050, $66 \%$ of the world's population is projected to be urban (UN 2014). Megacities get much of the attention; however, close to half of the world's urban dwellers reside in relatively small cities of less than 500,000 inhabitants, and only around one in eight lives in the 28 megacities with more than 10 million inhabitants (UN 2014, p. 1). Unquestionably, this trend of rising population density in the cities of the world is accompanied by a concentration of risk.

Even in the face of challenges, cities are proving to be a bright spot in governance. They are serving as incubators of innovative approaches to managing complex problems. Closest to the action and real estate, cities are proving to be nimble. Optimistically, Glaeser (2011, p. 50) writes in Scientific American: “... the crush of people living in close quarters fosters the kind of collaborative creativity that has produced some of humanity's best ideas, including the industrial revolution and the digital age. In the years ahead such collaborations can be expected to help solve the world's most pressing problems."

Latent capacity at the local level is promising, especially when leveraged by increasing global capacities. A closer assessment of the dynamics of this capacity can reveal where augmentation is needed. March (1991) laid out an elegant framework that helps explain the variations in local governance and DRM by contrasting concepts of exploration and exploitation:

Exploration includes things captured by terms such as search, variation, risk taking, experimentation, play, flexibility, discovery, innovation. Exploitation includes things such as refinement, choice, production, efficiency, selection, implementation, execution.
Adaptive systems that engage in exploration to the exclusion of exploitation are likely to find that they suffer the costs of exploration without gaining many of its benefits[...] Conversely, systems that engage in exploitation to the exclusion of exploration are likely to find themselves trapped in suboptimal stable equilibria. As a result, maintaining an appropriate balance between exploration and exploitation is a primary factor in system survival and prosperity (March 1991, p. 71).

A balance of explorative and exploitive capacities is critically important in DRM, most notably through early detection of change, flexibility in decision making in combination with dense patterns of cooperative action, and the ability to reorganize (King 1995; La Porte 1996; Duit and Galaz 2008). Nevertheless, maintaining a DRM capacity can be costly.

Finding the correct balance between anticipation and resilience is a fundamental process explained by Wildavsky (1988). On the one hand resources could be expended needlessly to develop unnecessary capacity, or in the other extreme, capacity may not be sufficiently established. In either case, a prudent and balanced approach for the expenditure of limited resources safeguards that they are used sustainably over time.

The key for local governance is that much of what is required to develop an appropriate level of DRM can be accessed through the emerging system of globalized DRM. Local governance mechanisms can access, integrate, and adapt DRM components as needed. Access to a globalized DRM system is particularly relevant for the vast numbers of smaller cities, where risks can be high and DRM capacity may be limited.

By linking global and local resources, DRM capacities can be sufficiently leveraged to meet the challenges presented by rapid urbanization and its associated risks. Amid the natural formation of global-local linkages, a valuable facilitating role remains for national level governance in the process.

\section{National Governance and Strategic Opportunities}

Much has been written over the last 20 years about the decline of the state. The central notion is that as a country becomes more globalized, sovereignty tends to migrate away from the state. The drift transpires through a variety of underlying forces including economic ties, increased international obligations through treaties, and more actors on the national stage. However, as Mark Twain once stated in response to news of his demise, "The report of my death was an exaggeration." 
While the drivers of the national level change are complex, new opportunities can also emerge upon which enlightened states can act strategically. As Castells describes,

[...] the actual system of governance in our world is not centered around the nation-state, although nationstates are not disappearing by any means. Governance is operated in a network of political institutions that shares sovereignty in various degrees and reconfigures itself in a variable geopolitical geometry. This is what I have conceptualized as the network state. It is not the result of technological change, but the response to the structural contradiction between a global system and a national state (Castells and Cardoso 2005, p. 15-16).

The power of the state in the twenty-first century will vary widely from country to country, and from time to time. In general, success is found when the state is able to move strategically to resolve a crisis or exploit an opportunity.

The term "governance" comes from the Greek $k u$ bernáo which means to steer or direct, but there is no consensus on the definition of governance among any researchers or practitioners. Definitions range from statecentered to society-centered views that incorporate a wide range of institutional arrangements by which we organize our collective lives. Nevertheless, a broad perspective on governance is helpful in view of the shifting trends of governance toward the inclusion of the wide range of institutions. The state is certainly central to the transformation of the collective organization, and is vested with a range of enabling powers and assets (McCarney et al. 1995; Carmichael 2002).

The comprehensive view of governance enables a move from a state-centric approach to building capacity. An aptitude at the national level to sufficiently integrate the globalized system is key for capacity building. Capacity does not need to reside in government itself, but can exist in the larger community, in an umbrella arrangement with the country, regional, or international bodies.

The changing role of national governance is a critical point in understanding the rapidly evolving systems for DRM. Moving strategically in the twenty-first century will involve constructively linking local and global capacities, where the state is well positioned to play a facilitating role and remain in a central position. The coordinating and regulatory role is another critical responsibility of the nation-state. Indispensably, these functions can provide the stability for the system of networked relationships to function optimally (Castells 2009).

There may be hesitancy by some countries to the opening of the state to the scrutiny of a globalized system in DRM. The idea of "thick" globalization (Barnett 2005) is characterized by network connectivity, financial transactions, liberal media flows, and collective security arrangements. In contrast, "thin" globalization (Barnett 2005) allows politically repressive regimes to flourish with little scrutiny and results in underdevelopment, economic stagnation, and unstable societies. As a consequence, some nations may be reluctant to openly embrace this globallocal function.

\section{Toward a New Global-Local Disaster Risk Management}

Few practical options exist in a limited resource environment for building widespread DRM commensurate with the concentrations of risk. A realistic opportunity is a state facilitated connection and integration of the local level and its latent capacities to the wealth of global capabilities. In building this capacity, networks will be better positioned to derive their own DRM solutions. It is in the interrelationships of these dynamics that the DRM capacities are augmented. Further, it is the same interdependence within these networks that potential solutions may be found (Ball 2011). Similarly, Wildavsky (1988) states, "The organism or social system that can, from its supply of basic resources, synthesize what it needs whenever new dangers arise is in a much stronger position to cope with unexpected consequences or with hazards that only occasionally manifest themselves" (Wildavsky 1988, p. 71). Building local DRM capacity from within, enabled by a globalized DRM system ably facilitated by the national level, is thus the key to moving forward.

Education, and higher education in particular, is essential in building DRM capacity at all levels. Einstein observed that, "No problem can be solved from the same level of consciousness that created it." There is a need to educate a new type of worker, one that can move beyond the "level of consciousness" that contributed to increasing risk in cities. Castells and Cardoso hold that "[at the] source of the entire process of social change there is a new kind of worker, the self-programmable worker, and a new type of personality, the values-rooted, flexible personality able to adapt to changing cultural models along the life cycle because of her/his ability to bend without breaking, to remain inner-directed while evolving with the surrounding society (Castells and Cardoso 2005, p. 18). Higher education can be instrumental in bringing about the kind of transformation necessary for a workforce which can guide DRM at all levels, with the ability to deliver high quality low cost DRM programs across the globe.

To accompany a wide diffusion of education, a system enhancing information flow would be central to linking a 
globalized DRM system to local needs. The Global Redesign Initiative of the World Economic Forum (WEF 2011) identified options for restructuring a global approach to disasters. Most of the identified options involved creating new international organizations or restructuring existing ones. However, one option focused on collaborative network processes, similar to what is emerging in a globalized DRM system and the broader "adaptable multi-lateral sprawl." For the WEF, the key to network functioning is enhancing information flow through "[a] process that aggregates the risk related information produced by existing organizations into a more integrated whole, with the intent of creating a more balanced and comprehensive picture of the overall array of global risks" (WEF 2011, p. 297).

The initial aim is to recognize and value the dynamic connections, along with the constituent parts of DRM and associated nature of risk. "Planning for the future might not be so much a matter of foreseeing what could go wrong as of making our systems and institutions robust enough to withstand a variety of shocks. This is how the new history will work" (Ball 2011, p. 448). Therefore, accessing and applying the globalized DRM system to the unique requirements of a particular locale will require a wide diffusion of high quality education and training in DRM at all levels, supported by a system that can facilitate information flow.

Building the appropriate level of networked global-local capacity will be critical for DRM in the twenty-first century. The linkages of the system at the global and local levels can be established. The key is how the national level will exercise its strategic role in bringing these capacities to bear on the complex issues of DRM. The task now is to "dig the well before we need the water."

Open Access This article is distributed under the terms of the Creative Commons Attribution License which permits any use, distribution, and reproduction in any medium, provided the original author(s) and the source are credited.

\section{References}

Ball, P. 2011. Crisis response: The new history. Nature 480(7378): $447-448$.

Barnett, T. 2005. The Pentagon's new map: War and peace in the twenty-first century. New York: Penguin.

Carmichael, P. 2002. Review of public administration briefing paper: Multi-level governance. http://www.rpani.gov.uk/multilevel.pdf. Accessed 26 Jan 2015.
Castells, M. 1996. The rise of the network society, the information age: Economy, society and culture, vol. I. Cambridge, MA: Blackwell.

Castells, M. 2008. The new public sphere: Global civil society, communication networks, and global governance. Annals of the American Academy of Political and Social Science 616(1): $78-93$.

Castells, M. 2009. Communication power. Oxford, UK: Oxford University Press.

Castells, M., and G. Cardoso. 2005. The network society: From knowledge to policy. Washington, DC: Johns Hopkins Center for Transatlantic Relations.

Cleveland, H. 2002. The future is uncentralized. Public Administration Review 60(4): 293-297.

Duit, A., and V. Galaz. 2008. Governance and complexity: Emerging issues for governance theory. Governance: An International Journal of Policy, Administration, and Institutions 21(3): 311-335.

Glaeser, E. 2011. Cities: Engines of innovation. Scientific American 305(3): 50-55.

King, A. 1995. Avoiding ecological surprise: Lessons from longstanding communities. The Academy of Management Review 20(4): 961-985.

La Porte, T. 1996. High reliability organizations: Unlikely, demanding, and at risk. Journal of Contingencies and Crisis Management 4(2): 60-67.

March, J. 1991. Exploration and exploitation in organizational learning. Organization Science 2(1): 71-87.

McCarney, P., M. Halfani, and R. Stren. 1995. Towards an understanding of governance: The emergence of an idea and its implications for urban research in developing countries. In Urban research in developing countries, ed. R. Stren, 95-98. Toronto: Centre for Urban and Community Studies, University of Toronto.

NRC (National Research Council). 2007. Improving disaster management: The role of IT in mitigation, preparedness, response, and recovery. Washington, DC: The National Academies Press.

Patrick, S. 2014. The unruled world: The case for good enough global governance. In Foreign Affairs January/February 2014. http:// www.foreignaffairs.com/articles/140343/stewart-patrick/theunruled-world. Accessed 26 Jan 2015.

UN (United Nations), Department of Economic and Social Affairs, Population Division. 2014. World urbanization prospects: The 2014 revision highlights (ST/ESA/SER.A/352).

Wildavsky, A. 1988. Searching for safety. New Brunswick, NJ: Transaction Books.

WHO (World Health Organization). 2015. Report by the DirectorGeneral to the Special Session of the Executive Board on Ebola. 25 January 2015. Geneva, Switzerland. http://www.who.int/dg/ speeches/2015/executive-board-ebola/en/. Accessed 17 Feb 2015.

WEF (World Economic Forum). 2011. Global redesign initiative. http://www.weforum.org/issues/global-redesign-initiative/index. html. Accessed 17 Feb 2015.

WEF (World Economic Forum). 2014. Global risk report. http://www. weforum.org/reports/global-risks-2014-report. Accessed 26 Jan 2015. 